\title{
Exploring the applicability and limitations of selected optical scattering instruments for PM mass measurement
}

\author{
Jie Zhang, Joseph P. Marto, and James J. Schwab \\ Atmospheric Sciences Research Center, University of Albany, State University of New York, NY, USA
}

Correspondence: Jie Zhang (jzhang35@albany.edu)

Received: 20 December 2017 - Discussion started: 5 February 2018

Revised: 20 April 2018 - Accepted: 26 April 2018 - Published: 22 May 2018

\begin{abstract}
Two optical scattering instruments for particle mass measurement, the Thermo Personal Data RAM (PDR1500) and the TSI Environmental DustTrak DRX (Model 8543) were evaluated by (1) using poly- and mono-disperse test aerosol in the laboratory, and (2) sampling ambient aerosol. The responses of these optical scattering instruments to different particle characteristics (size, composition, concentration) were compared with responses from reference instruments. A Mie scattering calculation was used to explain the dependence of the optical instruments' response to aerosol size and composition. Concurrently, the detection efficiency of one Alphasense Optical Particle Counter (OPCN2) was evaluated in the laboratory as well. The relationship between aerosol mass concentration and optical scattering was determined to be strongly dependent on aerosol size and to a lesser extent on aerosol composition (as reflected in the refractive indices of the materials tested) based on ambient measurements. This confirms that there is no simple way to use optical scattering instruments over a wide range of conditions without adjustments based on knowledge of aerosol size and composition. In particular, a test period measuring ambient aerosol with optical scattering instruments and a mass based method (an Aerodyne Aerosol Mass Spectrometer) determined that roughly two thirds of the variance $\left(R^{2}=0.64\right)$ of the optical to mass signal ratio is explained by the aerosol mass median diameter alone. These observations and calculations help evaluate the applicability and limitations of these optical scattering instruments, and provide guidance to designing suitable applications for each instrument by considering aerosol sources and aerosol size.
\end{abstract}

\section{Introduction}

The measured mass concentration of fine particulate matter $\left(\mathrm{PM}_{2.5}\right)$ both indoors and outdoors is important for many reasons (Chow et al., 2005; McMurry, 2000; Bae et al., 2010; Brauer et al., 2011). A major reason is that fine particulate matter is associated with adverse effects on human health, specifically increased morbidity and mortality rates (Dockery et al., 1993; Landen et al., 2011). The standard mass concentration measurement method established by the US Environmental Protection Agency (EPA) for compliance with National Ambient Air Quality Standards (NAAQS) is based on gravimetric filter sampling and weighing (Sousan et al., 2016a), which are repeatable and have well characterized accuracy and precision. However, these methods cannot provide real-time aerosol mass concentration, which limits the information available regarding aerosol sources, diurnal variation (Wallace et al., 2011), and high concentration spikes of short duration (Chung et al., 2001).

These drawbacks can be avoided by using real-time continuous instruments, most commonly the tapered element oscillating microbalances (TEOM) or beta attenuation monitors (BAM) (EPA, 2013). However, due to the high cost and large size of these instruments, it is difficult to deploy these real-time instruments for quick-response situations or in a wide spatial coverage, especially in remote areas and developing countries. Less expensive, portable, small sensors which use light scattering to infer particle mass concentration have become available in the past few decade, and they are currently drawing much attention as an alternative to the well established methods described above (Hinds et al., 1999; Holstius et al., 2014; Wang et al., 2015, 2016). These portable sensors can provide high-resolution real-time data, be deployed in dense networks at reasonable costs and 
also they are suitable for vertical aerosol profile measurement lunched on small balloon or aircraft (Mamali et al., 2017).

Typically, these light scattering sensors are calibrated by the manufacturer using a specific test aerosol, which may or may not be representative of ambient testing conditions at a given location. For this reason, there is ongoing interest in evaluating the capabilities and limitations of optical scattering sensors in the laboratory when challenged with aerosol of varying sizes and compositions (Crilley et al., 2018; Holstius et al., 2014; Li and Biswas, 2017; Sousan et al., 2016a; Wallace et al., 2011; Wang et al., 2015). Sousan et al. (2016b) found the OPC-N2 (Alphasense Ltd) performed similarly to the PAS-1.108 (portable aerosol spectrometer, Grimm Technologies, 2010, also an optical particle counter) for particles with diameter above $1 \mu \mathrm{m}$. In other studies, laboratory measurements were complemented by field comparisons with reference instruments (such as TEOM or gravimetric filter methods). Wallace et al. (2011) suggested a calibration factor of 0.38 for the DustTrak when sampling ambient aerosol after comparing the instrument with TEOM data. Crilley et al. (2018) evaluated the performance of OPC-N2 for ambient measurements in $\mathrm{UK}$, and a reasonable agreement was found comparing to reference instruments. Feinberg et al. (2018) shows high correlations between optical PM sensors (such as AirCasting AirBeam, Shinyei PMSSYS-1 etc.) and reference monitors in Denver, Colorado, USA.

Investigating the fundamental performance of these optical instruments for different kinds of aerosol aids in understanding their properties and guiding their suitable use. Based on these considerations, experiments were designed and performed to evaluate three distinct optical sensors-the Thermo Personal DataRAM (PDR-1500), the TSI Environmental DustTrak DRX (Model 8543), and the Alphasense Optical Counter (OPC-N2) using mono-disperse aerosol to study the instrument's dependence on particle size, and polydisperse test aerosol to study the effect of aerosol refractive index (related to chemical composition). A Mie scattering calculation was used to quantitatively describe the performance of these instruments. Optical instruments readings were then related to the aerosol mobility diameter measured by scanning mobility particle sizer (SMPS) and chemical composition of non-refractory ambient aerosol measured by a high-resolution time-of-flight aerosol mass spectrometer (HR-TOF-AMS) to provide detailed analysis of the effects of ambient size and chemical composition on the response of these optical instruments. Using these laboratory results, the average refractive index of the ambient aerosol was estimated based on the response of optical instruments and the aerosol size distribution.

\section{Methods}

\subsection{Instrumentation}

The TSI DustTrak DRX (model 8543, hereafter DRX) is a combined photometer and optical counter, which uses a $655 \mathrm{~nm}$ laser to illuminate a sample stream and measures the intensity of scattered light perpendicular to the stream with a photodetector (Wang et al., 2009; TSI Inc., 2017). Its scattering angle is $90^{\circ}$. The measured intensity is a function of the total particle volume, the particle refractive index, and the particle shape (Wallace et al., 2011). The measurable mass range (software determined) is 0.001 to $150 \mathrm{mg} \mathrm{m}^{-3}$, and size range is 0.1 to $10 \mu \mathrm{m}$. Scattering intensities of individual particles are used to group particles into broad size bins - typically $\mathrm{PM}_{1}, \mathrm{PM}_{2.5}, \mathrm{PM}_{4}$, and $\mathrm{PM}_{10}$. The total flow rate of the DRX was set to 3 LPM, with 2 LPM of this total flow as measured aerosol sample flow, while the other 1 LPM is filtered and used as sheath flow (TSI Inc., 2017). The DRX is calibrated by TSI using ISO 12103-1, A1 Arizona test dust. The default calibration factor of 1 was used for this study.

The PDR-1500 (Thermo Fisher Scientific Inc., 2014, hereafter PDR) is a highly sensitive nephelometric monitor using an $880 \mathrm{~nm}$ wavelength LED source for particle scattering measurement. Its forward scattering angle covers 60 to $80^{\circ}$. The measurable mass range of PDR is 0.001 to $400 \mathrm{mg} \mathrm{m}^{-3}$, and its size range is 0.1 to $10 \mu \mathrm{m}$. During the measurement, the flow rate of PDR is set to 1.5 LPM. The PDR-1500 was factory calibrated against a gravimetric standard traceable to the National Institute of Standards and Testing (NIST) by the manufacturer using SAE Fine (ISO Fine) supplied by Powder Technology, Inc.

The OPC-N2 (Alphasense Ltd., www.alphasense.com, last access: 15 May 2018, hereafter OPC-N2) measures the intensity of light scattered from particles using an optical receiver at a forward angle of approximately $30^{\circ}$ (Sousan et al., 2016b). The light intensities are binned and reported as particle counts in 16 size bins from $380 \mathrm{~nm}$ to $17 \mu \mathrm{m}$. The laser wavelength of OPC-N2 is $658 \mathrm{~nm}$, and the total flow rate is 1.2 LPM, of which 0.22 LPM is used for the aerosol measurements. The maximum particle count rate is 10000 particle per second. The number and sizing of the OPC-N2 were calibrated by the manufacturer using polystyrene latex (PSL) particles and for ambient measurements a constant density of $1.65 \mathrm{~g} \mathrm{~cm}^{-3}$ is used for converting the volume concentration to mass concentration.

Our reference instruments included a TSI Scanning Mobility Particle Sizer (SMPS), which consisted of an Electrostatic Classifier (EC, model 3080), a Differential Mobility Analyzer (DMA, model 3081), and a Condensation Particle Counter (CPC, model 3785). The SMPS operated with a $10: 1$ sheath-to-sample flow ratio (sheath flow $3 \mathrm{~L} \mathrm{~min}^{-1}$, and sample flow $0.3 \mathrm{~L} \mathrm{~min}^{-1}$ ), which led to an effective measured aerosol mobility size range of 14.9 to $673.2 \mathrm{~nm}$. A tapered element oscillating microbalance (TEOM) mass mon- 
itor (R\&P Model 1400ab), provided continuous gravimetricbased non-volatile aerosol mass concentrations with a time resolution of 5 min (Hogrefe et al., 2004). An Aerodyne HRTOF-AMS (hereafter AMS) was also used to measure the chemical composition and mass size distributions of selected species in real time for non-refractory sub-micron aerosol (Drewnick et al., 2005; Sun et al., 2012). A collection efficiency (CE) factor of 0.5 was used to account for the aerosol loss caused by aerosol bounce at the vaporizer and aerosol lens transmission (Zhang et al., 2005, Canagaratna et al., 2007; Sun et al., 2009, 2011). The default relative ionization efficiencies (RIE) of organic compounds (1.4), nitrate (1.1), sulfate (1.2), ammonium (4), and chloride (1.3) were used (Jimenez et al., 2003; Lee et al., 2016). Aerosol density was determined from AMS measurements of the weighted contributions of major chemical species to the total mass concentration, as described in the Supplement.

\subsection{Experimental setup}

The experiments were conducted first as a laboratory evaluation, which evaluated the performance of optical sensors under controlled aerosol conditions, and second as ambient tests, which evaluated the performance of sensors under ambient aerosol conditions, including the effect of aerosol size and composition on sensor readings.

The laboratory setup used for evaluation and calibration of optical instruments has been described by Hogrefe et al. (2004) and is shown in Fig. 1. The laboratory system consisted of an aerosol generation and dilution system, as well as a $500 \mathrm{~L}$ aerosol chamber with sampling ports. The aerosol generation instrument was a constant output atomizer (TSI Model 3076). The dilution system reduced the aerosol mass concentration produced by the atomizer and dried the aerosol using dry air flow (generally below $10 \% \mathrm{RH}$, measured by PDR). Before sampling by the different instruments, the generated aerosol underwent equilibration in the aerosol chamber. The instruments sampled from the middle of the chamber, and about $20 \mathrm{~min}$ was required for the instruments to stabilize after each modification to the dilution or generation system. For evaluating the dependence of optical sensor performance on size, differently sized, mono-disperse PSL particles were used. For each size PSL, dilution liquid was incrementally added during measurement to vary concentration. After the PSL experiments, synthetic particles with four different chemical compositions $\left(\mathrm{NaNO}_{3},\left(\mathrm{NH}_{4}\right)_{2} \mathrm{SO}_{4}\right.$, sucrose, and adipic acid) were generated for testing the performance dependence on particle composition, as light scattering is affected by particle refractive index (Seinfeld and Pandis, 2016). For each material, the solution concentration and/or the amount of dilution air was varied during experiments to modify the concentration.

During these experiments, the TEOM was used as the reference instrument for $\mathrm{NaNO}_{3},\left(\mathrm{NH}_{4}\right)_{2} \mathrm{SO}_{4}$, sucrose, and PSL particles because it had the same sampling location as optical
Table 1. The scattering angles and light source wavelengths used in the DRX, PDR, and the OPC-N2, as well the approximate price of each sensor. USD: United States Dollar.

\begin{tabular}{lrrr}
\hline Sensor & DRX & PDR & OPC-N2 \\
\hline Wavelength (nm) & 655 & 880 & 658 \\
Scattering angle $\left(^{\circ}\right)$ & 90 & $60-80$ & 30 \\
Price (USD) & $\sim 10000$ & $\sim 5000$ & $\sim 500$ \\
\hline
\end{tabular}

instruments. The SMPS was used as the reference for adipic acid, due to adipic acid's high volatility (Mønster et al., 2004; Seinfeld and Pandis, 2016) and observed loss on the $50^{\circ} \mathrm{C}$ TEOM mass sensor.

For ambient experiments, two optical sensors (DRX and PDR), one HR-TOF-AMS, and one SMPS were connected to a dryer, to keep the RH below $40 \%$, and then connected to outside air through a vent port. The OPC-N2 was not used for these tests due to its size detection limit $(380 \mathrm{~nm})$ being larger than the most ambient aerosol of this study, while TEOM is not used due to its high frequency noise in ambient measurement.

\subsection{Mie scattering calculation}

The Mie scattering calculation followed the techniques in the MATLAB version of Mie theory for homogeneous spheres described by Mätzler (Mätzler, 2002). The required input parameters include the complex refractive index, the sphere radius, light wavelength, and the scattering angle ( $\mathrm{Li}$ and Biswas, 2017). Considering only spherical particles is reasonable in our situation because smaller non-spherical particles $(<1 \mu \mathrm{m})$ are more similar to their spherical phase than larger ones (Smith, 2009). The scattering angles and light wavelengths used in these three optical instruments are listed in Table 1 , and the scattering angle of $90^{\circ}$ for the PDR was used for simplicity. Using scattering angles between 60 and $80^{\circ}$ will change some details of the scattered flux, but the linearity of the scattered flux with aerosol amount will not be affected. Combining these sensor and aerosol parameters, the relative scattering flux per unit aerosol volume $\left(R_{-} \_v\right)$ for each particle size was then calculated. Knowing the normalized volume distribution (NVD) of the generated aerosol, the integrated relative flux (hereafter RF) expected to be received by the sensor detector was estimated by summing the product of RF_v and NVD over the whole particle size distribution. RF was then used to evaluate the performance of optical instruments and for comparison to measured mass concentrations. 


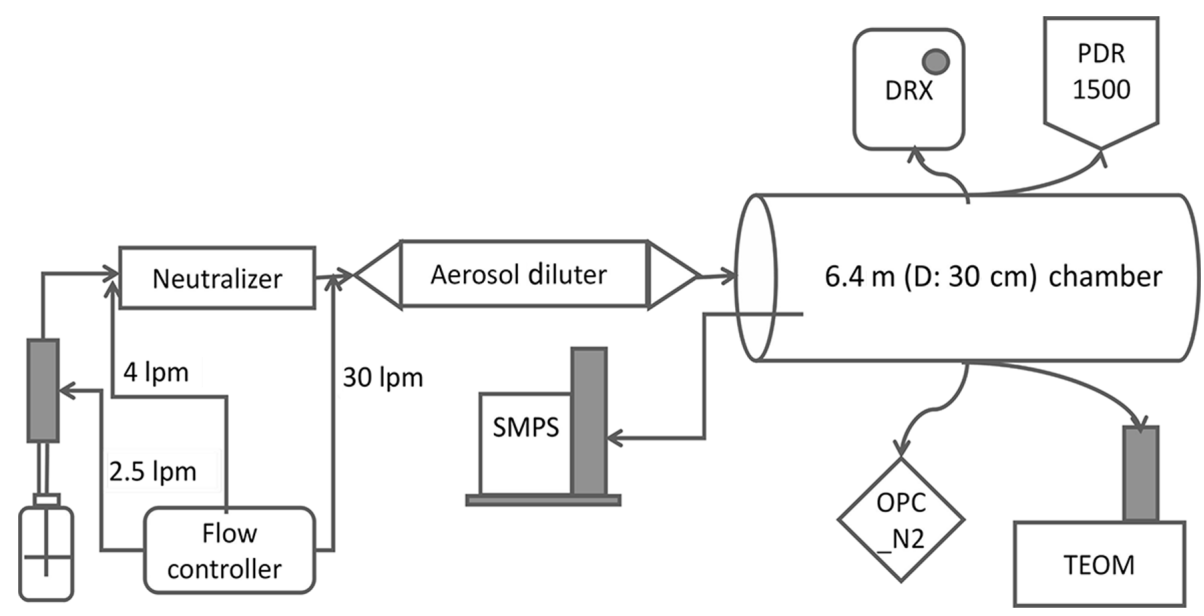

Figure 1. Laboratory setup used for the evaluation and calibration of optical instruments using poly- and mono-disperse test aerosol.
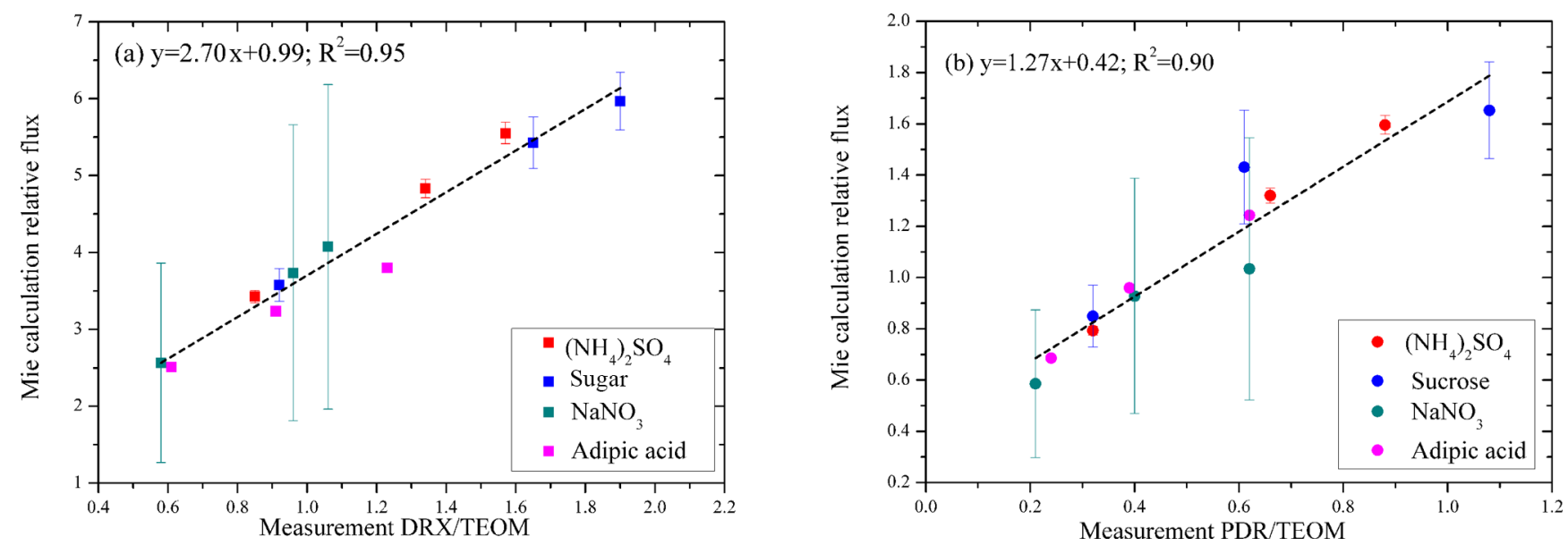

Figure 2. The relationship of the Mie scattering relative flux and the measurement ratio of optical sensors to TEOM, (a) DRX and (b) PDR.

Table 2. Slopes of the regression lines obtained when plotting optically reported PM values (for DRX, PDR, and OPC-N2); and calculated Mie scatter flux (for DRX_RF and PDR_RF) for different PSL sizes vs. the PM mass concentration measured by the TEOM. NA - not available.

\begin{tabular}{lrrrrr}
\hline Vs. TEOM & $90 \mathrm{~nm}$ & $173 \mathrm{~nm}$ & $304 \mathrm{~nm}$ & $490 \mathrm{~nm}$ & $1030 \mathrm{~nm}$ \\
\hline DRX & 0.86 & 0.90 & 3.73 & 2.56 & 0.93 \\
PDR & 0.32 & 0.28 & 1.34 & 3.14 & 1.30 \\
OPC-N2 & NA & NA & NA & 0.68 & 0.48 \\
RF results & & & & & \\
DRX_RF & 0.53 & 3.73 & 11.07 & 8.90 & 4.83 \\
PDR_RF & 0.09 & 0.63 & 2.92 & 5.30 & 3.70 \\
\hline
\end{tabular}

\section{Results and discussion}

\subsection{Performance with mono-disperse particles}

The dependence of DRX, PDR, and OPC-N2 performance on particle size was studied using five sizes $(90 \pm 14,173 \pm 9$, $304 \pm 9,490 \pm 15$, and $1030 \pm 31 \mathrm{~nm}$ ) of PSL particles (Ted Pella, Inc.). To compare optical sensors with the reference instrument (TEOM), $15 \mathrm{~min}$ of data collected at the end of each mass concentration plateau were averaged.

The relative responses of the optical sensors (PDR, DRX, and OPC-N2) compared to the TEOM for the monodispersed PSL particles are shown in Table 2. The outputs of these sensors were linearly regressed against particle mass concentration measured by the TEOM to get the ratio of optical sensor response to TEOM readings and all results were well correlated $\left(R^{2}>0.90\right)$. The results from the PDR and DRX for $304 \mathrm{~nm}$ PSL particles are shown in Fig. S1 in the Supplement as an example. As particle size increased in these experiments, the responses of the PDR and DRX showed 
a maximum for one specific size PSL (304 nm for DRX, and $490 \mathrm{~nm}$ for PDR). For both instruments, these sizes were closest to half of the light source wavelength used by the sensor. For OPC-N2, this maximum was missed due to its lower detection limit of $380 \mathrm{~nm}$. For PSLs large enough to trigger a response, the OPC-N2 detection efficiency was still lower than 1 for these two sizes; the detection efficiency was $68 \%$ for $490 \mathrm{~nm}$ and only $48 \%$ for $1030 \mathrm{~nm}$.

Mie scattering calculation results were used to explain the observed performance characteristics of the DRX and the PDR. The relative scattering fluxes from particles for conditions appropriate to the DRX and PDR are shown in Fig. S2 and Table 2. Figure S2a shows that the RF peaks at about $400 \mathrm{~nm}$ for DRX and $550 \mathrm{~nm}$ for PDR, which matches the results shown in Table 2 and as particle size increased beyond peak size, the relative scattering flux decreased. High correlation coefficients were obtained for regressions of RF vs. the optical instrument to TEOM signal ratio, with $R^{2}=0.97$ for DRX and 0.81 for PDR as shown in Fig. S2b. This is indicative of the general positive relation between the calculated RF with optical instrument's response to PSL. The values for $90 \mathrm{~nm}$ PSL are not used in this analysis, since both the DRX and PDR showed high response bias for $90 \mathrm{~nm}$ PSLs, which may be caused by the proximity of $90 \mathrm{~nm}$ to their detectors' size limits (100n m for DRX and PDR, Thermo Fisher Scientific Inc., 2014; TSI Inc., 2017), the uncertainty introduced by using a single scattering angle in the calculation, and/or the "non-PSL", very small aerosol generated when atomizing the PSL containing solution.

\subsection{Performance with poly-disperse particles}

\subsubsection{Mass concentration dependence on particle composition}

To focus on the instruments' dependence on particle composition (mainly the effect of refractive index), three groups of tests with different concentration liquid samples were performed and are shown in Table S1 in the Supplement. The changes in solution concentration produced a shift in aerosol number/mass size distribution sampled by the instruments. In each of the three groups, concentrations were selected such that the volume size distributions of the four compounds were very similar (as shown in Fig. S3).

The ratios of readings from the optical instruments to those of the reference instruments for different kinds of aerosol in each group were determined, and are shown in Table 3. A strong, linear relationship between the DRX, PDR, and OPC-N2 with the TEOM for $0.45 \mathrm{gL}^{-1}$ (atomizer solution concentration) sucrose (density $1.59 \mathrm{~g} \mathrm{~cm}^{-1}$ ) was found, with $R^{2}=0.99$ for all three optical sensors, as shown in Fig. S4 as an example. For the other groups of particles and concentrations tested, the results were similar. This illustrates the high linearity of the responses of these optical instruments when challenged with pure substances of a stable particle size distribution.

Table 3 shows the variation of optical to mass ratios related to the aerosol composition in each group, in addition to an inter-comparison between different groups. For low dilution concentrations (Group 1), the DRX showed a higher response (ratio vs. TEOM) for sucrose (slope $=0.92)$, and $\left(\mathrm{NH}_{4}\right)_{2} \mathrm{SO}_{4}$ (slope $=0.85$ ), but lower ratios for $\mathrm{NaNO}_{3}$ and adipic acid (58 and $61 \%$, respectively). Similar performance was also shown for the PDR and OPC-N2. A lower detection ratio was observed for the OPC-N2, due to its detection limit (380 nm), as it would fail to detect many particles. Ratios of optical to mass signals for different particles are also related to their refractive index, and the aerosol with a larger refractive index results in a higher measurement ratio. More detailed discussion will be given in the next section, and the refractive indices of these materials are shown in Table 3 (Weast, 1976; Seinfeld and Pandis, 2016). For moderate and high concentrations, similar behavior was observed. Generally, the DRX and PDR produced higher optical to mass signal ratios for particles with larger refractive indices. It is worth noting that only bright aerosols were tested, meaning that the imaginary part of the refractive index of the aerosol was zero.

Since the median diameter of the volume size distributions increased from Group 1 to Group 3 as seen in Table S1, the increase in optical response shown in Table 3 verifies the size dependence illustrated by the PSL and presented in the previous section. That is, the response ratios of the optical instruments increase with increasing particle size for the same particle material in these three groups. Also, with increasing particle size, the difference between DRX and PDR decreased from about 2.7 times for the smallest median diameter, to 1.7 times for the largest median diameter. With size distribution shifting to larger sizes, the PDR displayed a larger relative response (to the TEOM) due to its longer wavelength light source.

\subsubsection{Mie scattering calculation for optical instruments}

For Mie scattering calculations, all particles were assumed to be spherical, and their refractive index was independent of wavelength over the range of interest. Refractive indices of the four materials are shown in Table 3. Some materials have two or three different refractive indices, the values of which are related to their crystal structure (Eggleton et al., 1991). To account for this effect, the relative scattering flux was calculated by using the maximum and minimum refractive indices, which produced a range of relative flux values for the material. The maximum and minimum relative fluxes were then averaged to represent a best estimate relative scattering flux of the material, and the difference between averaged value and minimum value was used as the error range. Following the above method, the relative Mie scattering flux of these four particle compounds was obtained for the optical sensors at different dilution concentrations as shown in 
Table 3. Ratios of mass concentration measured by optical instruments to reference instruments for the four compounds and groups listed in Table S1 (the median volume diameters are added below the name of different groups), as well as the refractive indices of each aerosol used in the Mie scattering calculations.

\begin{tabular}{llcccc}
\hline Ratio (vs. TEOM or SMPS) & $\left(\mathrm{NH}_{4}\right)_{2} \mathrm{SO}_{4}$ & $\mathrm{NaNO}_{3}$ & Sucrose & Adipic acid $^{\mathrm{a}}$ \\
\hline Refractive indices $(n)$ & $1.521 / 1.523 / 1.533$ & $1.587 / 1.336$ & $1.54 / 1.567 / 1.572$ & 1.439 \\
\hline Group 1 & DRX & 0.85 & 0.58 & 0.92 & 0.61 \\
$153 \mathrm{~nm}$ & PDR-1500 & 0.32 & 0.21 & 0.32 & 0.24 \\
& OPC-N2 & 0.026 & 0.015 & 0.018 & 0.01 \\
\hline Group 2 & DRX & 1.34 & 0.96 & 1.65 & 0.91 \\
$202 \mathrm{~nm}$ & PDR-1500 & 0.66 & 0.40 & 0.61 & 0.39 \\
& OPC-N2 & 0.09 & 0.07 & 0.08 & 0.03 \\
\hline \multirow{2}{*}{ Group 3 } & DRX & 1.57 & 1.06 & 1.90 & 1.23 \\
& PDR-1500 & 0.88 & 0.62 & 1.08 & 0.62 \\
& OPC-N2 & 0.2 & 0.14 & 0.17 & 0.09 \\
\hline
\end{tabular}

${ }^{a}$ SMPS was used as the reference measurement for adipic acid (see text).

Table S2. Here the Mie relative flux was only calculated for the DRX and PDR, and not the OPC-N2. This is because the DRX and PDR responses are directly related to the scattering flux, while the OPC-N2 response is directly related to the estimated aerosol number concentration, though its measured binned pulse is related to aerosol refractive index and aerosol size.

The highly correlated relationship of the Mie scattering relative flux and the measurement ratios of DRX and PDR to TEOM $\left(R^{2}=0.95\right.$ for DRX and 0.90 for PDR) shown in Fig. 2, verifies the linear relationship between RF and the ratio of optical to mass signals for this study and provides an explanation of the performance of DRX and PDR for the variation in particle composition and size. The particle with a higher refractive index (such as $\left(\mathrm{NH}_{4}\right)_{2} \mathrm{SO}_{4}$ and sucrose) or larger size distribution, produces a larger relative flux for optical instruments, resulting in higher instrument response and subsequently a higher measurement ratio of optical sensor readings to reference values.

\subsection{Detection efficiency of OPC-N2}

To evaluate the counting ability of OPC-N2 in more detail, the detection efficiency in the first size range channel $(380-540 \mathrm{~nm})$ of the OPC-N2 was analyzed. The limited size range was determined using the overlap of SMPS size range $(14.9-673.2 \mathrm{~nm})$ with OPC (detection limit of $380 \mathrm{~nm}$ ). Using the measurements from the OPC and SMPS size distributions, the particle number counts of these two instruments were calculated in the overlapping size range (380$540 \mathrm{~nm}$ ) in units of number per $\mathrm{cm}^{3}$. The comparison of OPC-N2 and SMPS measurement values is shown in Fig. 3. In the analysis, $\left(\mathrm{NH}_{4}\right)_{2} \mathrm{SO}_{4}$ readings showed saturation when OPC counts were higher than $300 \mathrm{~cm}^{-3}$. Excluding the saturated data, all four compounds $\left(\left(\mathrm{NH}_{4}\right)_{2} \mathrm{SO}_{4}, \mathrm{NaNO}_{3}\right.$, su-

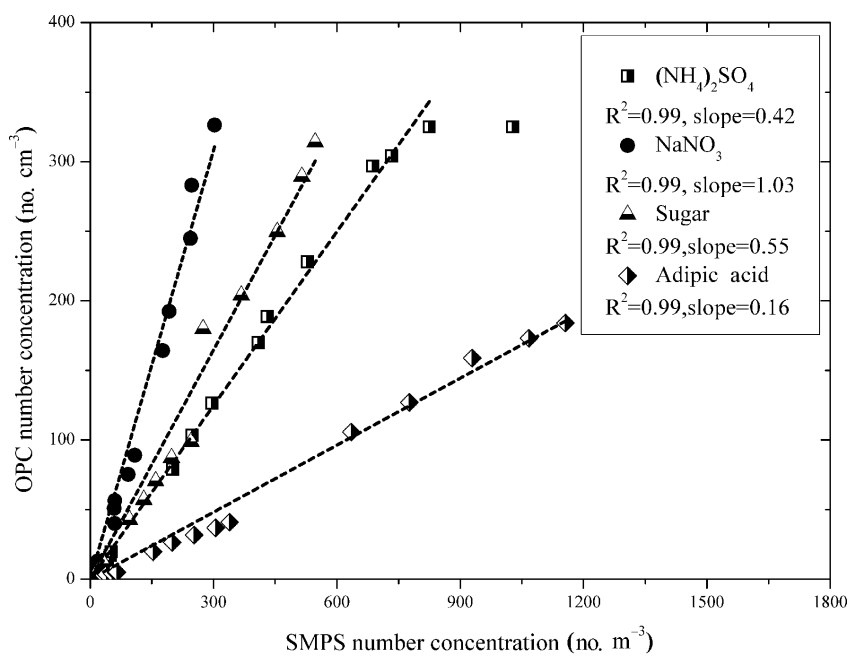

Figure 3. The comparison of OPC and SMPS counts for four kinds of aerosol in the $380-540 \mathrm{~nm}$ size range.

crose, adipic acid) displayed strong linear relationships between SMPS and OPC-N2 counts, with all $R^{2} \geq 0.99$.

As with the DRX and PDR, the number detection efficiency of the OPC-N2 showed substantial differences with aerosol composition. For $\mathrm{NaNO}_{3}$, the OPC-N2 number detection efficiency was as high as $103 \%$ when compared to the SMPS. However, it was only $42 \%$ for $\left(\mathrm{NH}_{4}\right)_{2} \mathrm{SO}_{4}, 55 \%$ for sucrose, and $16 \%$ for adipic acid. The low number detection efficiency of the OPC-N2 for many of these compounds helps explain the low ratio of the OPC to SMPS in Table 3.

\subsection{Ambient measurement}

Ambient measurements were recorded from 22 December 2016 to 1 July 2017, and from 27 September 2017 to 10 Jan- 


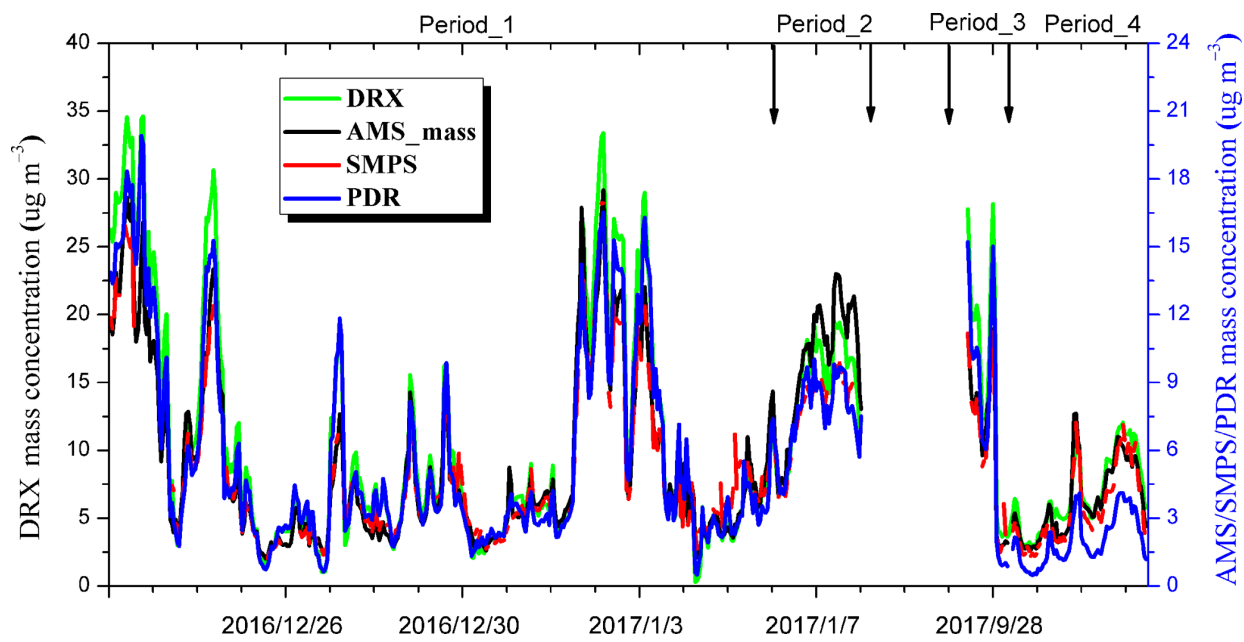

Figure 4. The time series of $1 \mathrm{~h}$ aerosol concentration measured by DRX, PDR, AMS, SMPS from 22 December 2016 to 1 July 2017 and 27 September 2017 to 10 January 2017.

uary 2017 to study the performance of PDR and DRX under ambient aerosol conditions. The time series of $1 \mathrm{~h}$ aerosol concentration readings of the DRX, PDR, AMS, and SMPS are shown in Fig. 4, and the aerosol chemical species mass concentrations and mass fractions are shown in Fig. S5.

Figure 4 shows very similar behavior (that is, high and low excursions) for the DRX, PDR, SMPS, and AMS measurements. AMS measurements showed high correlation $\left(R^{2}=\right.$ 0.94) with SMPS mass concentration, and the regression slope $=0.85$ as shown in Fig. S6a. The $15 \%$ difference between the AMS and SMPS may be the result of the bias of the estimated aerosol density or the CE factor used by AMS. The high correlation verifies the performance of AMS for these periods and its reliability as a reference instrument. The even higher coefficient of determination $\left(R^{2}=0.96\right)$ between the PDR and the DRX (Fig. S6b) shows the comparability of these two optical instruments and the slope of 1.81 is due to the different factory calibration factors for the instruments. Of all the DRX vs. PDR data in Fig. S6b, there was one set of data points clearly deviating from the main cluster and these data points came from 28 September 2017 02:00 to the end of this study. At that date and time, a cold front passed through Albany, causing aerosol mass concentration to drop quickly, from about 11 to $2 \mu \mathrm{g} \mathrm{m}^{-3}$ and aerosol mass median diameter (measured by SMPS) dropped from 280 to $200 \mathrm{~nm}$, while the organic compound fraction increased to above $80 \%$, as shown in Fig. S5. This deviation shows the influence of aerosol characteristics (mainly aerosol size here) on the optical instruments. The comparisons between the optical instruments with AMS are shown in Fig. 5. The PDR data shows a little more scatter than the DRX data $\left(R^{2}=0.86\right.$ vs. 0.91$)$, and the slope of PDR to AMS was 1.03 (near to 1), while the slope of DRX to AMS was 1.96, indicating a calibration factor of 0.52 for the DRX would be appropriate for this data. This calibration factor is higher than that recommended by the manufacturer for ambient aerosol (0.38, TSI Inc., 2017; Wallace et al., 2011). This difference in recommended calibration factor based on aerosol size and composition is an important result and deserves to be widely recognized.

The combination of aerosol median diameter, aerosol chemical mass fractions, and the ratio of optical instrument values to AMS mass concentrations can be used to verify the above assumption that the aerosol size is the most important variable in this study. Plots combining these parameters are shown in Fig. 6 (PDR) and Fig. S7 (DRX). Figure 6 shows the correlation scatterplot of aerosol median diameter plotted vs. the PDR/AMS ratio. All points are color coded by organic mass fraction, and sized by AMS mass concentration. A moderate coefficient of determination $\left(R^{2}=0.64\right)$ with positive slope indicates the clear relationship between mass median diameter and PDR/AMS ratio. The random distribution of organic-rich (red) points and inorganic-rich (blue) points in Fig. 6 and Fig. S7 suggests aerosol composition has a smaller effect on the response of these optical instruments. For example, the organic mass fraction corresponding to DRX/AMS ratio $=1$ ranged from 0.3 to 0.8 in Fig. S7. Figure 6 does show clustered organic-rich particles in the smaller size range (lower left points), as well as inorganic-rich particles in the large size range (upper right points). A likely reason for this is that the small size range particles were newly emitted fresh aerosol that was characterized by very high organic fraction, small-size distribution and externally mixed properties (note that organics had a small second peak at about $150 \mathrm{~nm}$, Fig. S8a, Sun et al., 2009), while the large particles were related to aged regionally representative aerosol, characterized by higher $\mathrm{SO}_{4}$ mass fraction, large-size organic/ $\mathrm{SO}_{4}$ mass distribution, as well as internally mixed properties (both peak about $400 \mathrm{~nm}$, Fig. 8b, Sun et al., 2009). 

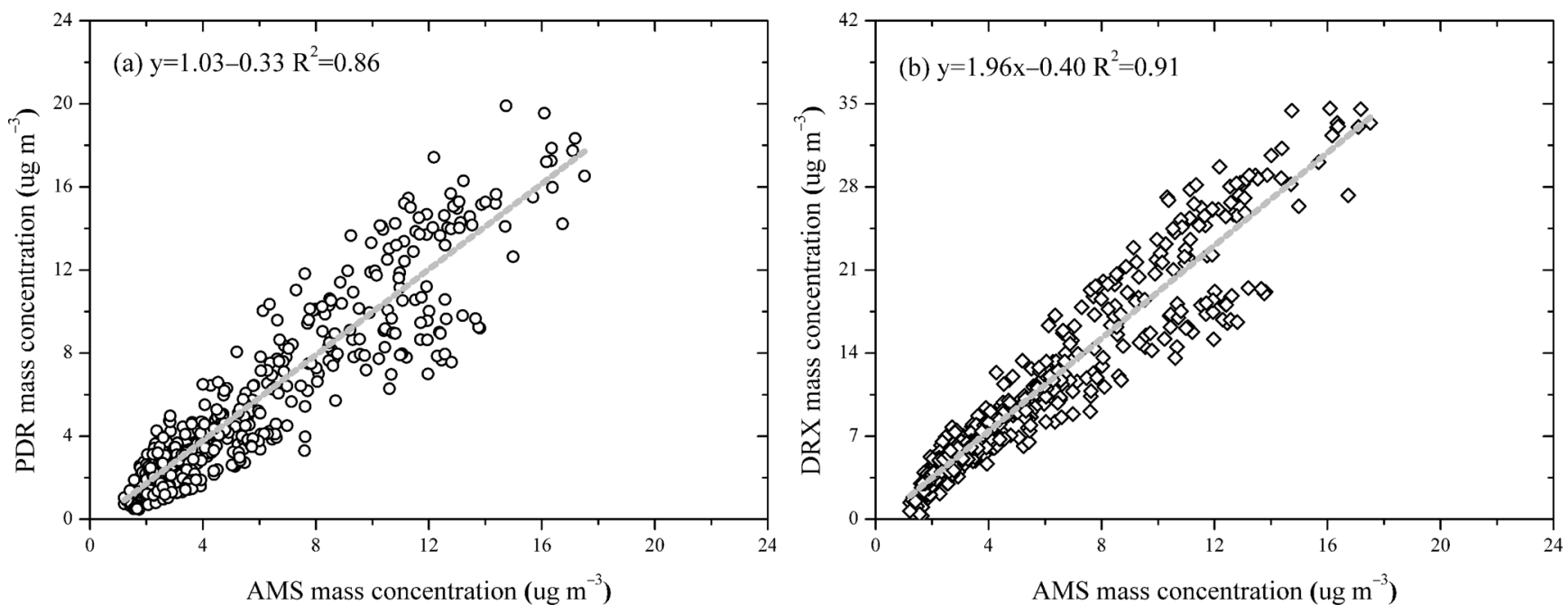

Figure 5. The comparison of the $1 \mathrm{~h} \mathrm{PM}_{2.5}$ average concentration between PDR (a) and DRX (b) observations with AMS measurements.

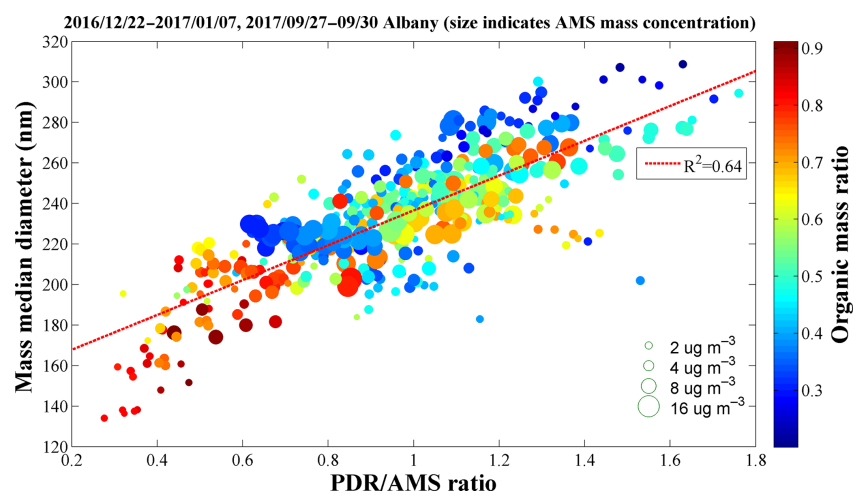

Figure 6. The correlation scatterplot of aerosol median diameter and the PDR/AMS ratio. All points are colored by organic mass fraction, and sized by AMS mass concentration.

The dependence of the optical sensors on aerosol size highlights an important consideration for the use of optical scattering sensors in critical applications. It is clear that different correction factors should be used in different measurement conditions instead of a single constant value (McNamara et al., 2011). For example, the PDR, when used in a rural forest environment with high concentrations of fresh organic-rich small size aerosol, the response ratio may be as high as 2.50 based on the results of this study, while for an area which would be strongly impacted by aerosol transported long distances, such as the northern US regions affected by long-range transported wood-fire produced aerosol from western Canada (Le et al., 2014) or biomass-burning aerosol from of the central US (such as the Mississippi Valley, Zhang et al., 2008), the correction factor could be as low as 0.60 . These lowest response ratios might be expected when Albany was affected by biomass-burning aerosol from southern Mississippi Valley as shown in Fig. S9.

\subsection{Ambient aerosol refractive index estimation}

Assuming the relationship between RF and the ratio of optical instruments to reference instruments is constant for lab tests of pure composition aerosols (Fig. 2) and ambient aerosol, the average ambient aerosol refractive index real part can be derived. The averaged RF of optical instruments is calculated based on that linear relationship and the ratio of optical or AMS signals. From this a reference table of RF for different refractive indices can be built based on the normalized volume size distribution and the assumed differences in refractive index (from 1.2 to 1.8 with step of 0.01), as shown in Table S3. After comparing the calculated RF with the RF in the reference table, the refractive index of the ambient aerosol may be estimated. Figure S10 shows the estimated time series of $1 \mathrm{~h}$ refractive index real part using the above method based on PDR and DRX data. Generally, the relative difference between these two estimations was below $10 \%$, with the largest discrepancy after 28 September 2017. A likely explanation of this larger difference is the smaller particles in this period biasing the optical instruments relative responses. The averaged value determined for the refractive index was 1.54 for PDR and 1.55 for DRX, which was very near to the estimated value 1.56 (Hand et al., 2002) and within the estimated range of 1.54 to 1.72 (Ebert et al., 2004). The correlation scatter plot of aerosol refractive index and the PDR/AMS ratio (Fig. S11a) verifies the smaller effect of refractive index on PDR/AMS ratio compared to aerosol size, with a similar result for the DRX (Fig. S11b). One possible reason for this is that the range of variation of refractive index of this study was relatively small (88\% points in $1.48-1.58$ ), which was not enough to cause significant variation in the optical instrument responses. 


\section{Conclusions}

In this study, the performance of three optical sensors (DRX, PDR, and OPC-N2) was evaluated using (1) poly- and monodisperse aerosol in the lab, and (2) ambient aerosol (PDR and DRX only). The aim of this evaluation was to study the applicability and limitations of each optical sensor. A Mie scattering calculation was used to describe the results of these measurements. During laboratory tests, good linear relationships (generally $R^{2}>0.90$ ) were shown between the optical measurements and the traditional mass measurements, while the slope depended on aerosol size and aerosol composition. The response of these optical instruments can be well explained by the Mie scattering calculations. During the mono-disperse particle tests, the DRX was more sensitive to smaller particles than the PDR, which is consistent with its shorter wavelength light source. During the poly-disperse particle experiments, all three sensors showed higher responses for sucrose and $\left(\mathrm{NH}_{4}\right)_{2} \mathrm{SO}_{4}$, and lower responses for $\mathrm{NaNO}_{3}$ and adipic acid, which illustrates the important effect of refractive index (or particle chemical composition) on instrument performance. The aerosol with higher refractive index or larger size produced more scattering flux, and therefore a higher instrument response.

During ambient aerosol experiments, the DRX and PDR were directly compared to the reference instruments (SMPS and AMS). By exploring the aerosol mass median diameter measured by SMPS and combining the mass fraction loading of aerosol compounds measured by AMS, we found aerosol size (represented by aerosol mass median diameter) has the greatest impact on the relative optical response in this study when compared to the chemical composition of the aerosol compounds and the aerosol refractive index. The aerosol refractive index was estimated based on the relationship of RF with the ratio of optical instruments to reference instruments, the normalized volume size distribution, and a reference table.

The dependence of the optical sensors on aerosol size highlights an important consideration about aerosol size distribution in the use of optical scattering sensors. For field ambient aerosol measurements, the characteristics of aerosol sources, such as traffic emissions or forest-based new particle formation may affect on the quality of the sensor data. Knowledge of the size distributions of aerosol from former studies would help to determine more accurate calibration factors for optical instruments. However, due to the limit of SMPS measurements (upper size limit $<700 \mathrm{~nm}$ in our case) and AMS measurements (upper size limit $<1000 \mathrm{~nm}$, and only detects non-refractory species), the relatively short time period of measurements in this study and a lack of diversity of aerosol sources, more ambient measurements will be necessary to more fully map out the range of calibration factors required for the application of optical instruments. This study mainly focused on dry aerosol (the detected aerosol RH by PDR in lab is below $10 \%$ and during ambient measurements the dryer kept the RH below $40 \%$ ), the dependence of optical instruments on RH needs further study. Despite the complexity of determining calibration factors, as well as instrument limitations, these compact optical instruments will hopefully provide increasingly reliable data covering a greater spatial extent. Additional studies and measurements will help better characterize the aerosol, and it is hoped they will provide further accurate information that will help inform and design plans to improve ambient air quality.

Data availability. Original research data are available from the authors on request, and a public data query tool is in the process of being adding to our database and will be accessible at http:// atmoschem.asrc.cestm.albany.edu/ aqm/AQM_Products/ (Schwab et al., 2018).

\section{The Supplement related to this article is available online at https://doi.org/10.5194/amt-11-2995-2018-supplement.}

Competing interests. The authors declare that they have no conflict of interest.

Acknowledgements. This work has been supported by the New York State Energy Research and Development Authority (NYSERDA) contract number 48971. Special thanks go to research scientist Patricia Fritz (New York State Department of Health) for granting use of the PDR, Xiuli Wei, and Hui Shi for helping in the lab work, and Brian Crandall for assistance with the editing of this paper.

Edited by: Pierre Herckes

Reviewed by: three anonymous referees

\section{References}

Bae, M.-S., Schwab, J. J., Hogrefe, O., Frank, B. P., Lala, G. G., and Demerjian, K. L.: Characteristics of size distributions at urban and rural locations in New York, Atmos. Chem. Phys., 10, 45214535, https://doi.org/10.5194/acp-10-4521-2010, 2010.

Brauer, M., Amann, M., Burnett, R. T., Cohen, A., Dentener, F., Ezzati, M., Henderson, S. B., Krzyzanowski, M., Martin, R. V., Van Dingenen, R., Van Donkelaar, A., and Thurston, G. D.: Exposure assessment for estimation of the global burden of disease attributable to outdoor air pollution, Environ. Sci. Technol., 46, 652-660, 2011.

Canagaratna, M. R., Jayne, J. T., Jimenez, J. L., Allan, J. D., Alfarra, M. R., Zhang, Q., Onasch, T. B., Drewnick, F., Coe, H., Middlebrook, A., Delia, A., Williams, L. R., Trimborn, A. M., Northway, M. J., DeCarlo, P. F., Kolb, C. E., Davidovits, P., and Worsnop, D. R.: Chemical and microphysical characterization of ambient aerosols with the aerodyne aerosol mass spectrometer, Mass Spectrom. Rev., 26, 185-222, 2007. 
Chow, J. C., Watson, J. G., Savage, N., Solomon, C. J., Cheng, Y. S., McMurry, P. H., Corey, L. M., Bruce, G. M. Pleus, R. C., Biswas, P., and $\mathrm{Wu}, \mathrm{C}$. Y.: Nanoparticles and the Environment, JAPCA J. Air Waste Ma., 55, 1411-1417, 2005.

Chung, A., Chang, D. P., Kleeman, M. J., Perry, K. D., Cahill, T. A., Dutcher, D., McDougall, E. M., and Stroud, K.: Comparison of real-time instruments used to monitor airborne particulate matter, JAPCA J. Air Waste Ma., 51, 109-120, 2001.

Crilley, L. R., Shaw, M., Pound, R., Kramer, L. J., Price, R., Young, S., Lewis, A. C., and Pope, F. D.: Evaluation of a low-cost optical particle counter (Alphasense OPC-N2) for ambient air monitoring, Atmos. Meas. Tech., 11, 709-720, https://doi.org/10.5194/amt-11-709-2018, 2018.

Dockery, D. W., Pope, C. A., Xu, X., Spengler, J. D., Ware, J. H., Fay, M. E., Ferris, B. G., and Speizer, F. E.: An Association between Air Pollution and Mortality in Six US Cities, New Engl. J. Med., 329, 1753-1759, 1993.

Drewnick, F., Hings, S. S., DeCarlo, P., Jayne, J. T., Gonin, M., Fuhrer, K., Weimer, S., Jimenez, J. L., Demerjian, K. L., Borrmann, S., and Worsnop, D. R.: A new time-of-flight aerosol mass spectrometer (TOF-AMS) -Instrument description and first field deployment, Aerosol Sci. Tech., 39, 637-658, 2005.

Ebert, M., Weinbruch, S., Hoffmann, P., and Ortner, H. M.: The chemical composition and complex refractive index of rural and urban influenced aerosols determined by individual particle analysis, Atmos. Environ., 38, 6531-6545, 2004.

Eggleton, R. A.: Gladstone-Dale constants for the major elements in silicates: Coordination number, polarizability and the LorentzLorenz relation, Can, Mineral., 29, 525-32, 1991.

EPA: US. 40 CFR Parts 50, 51, 52, 53, and 58 - National Ambient Air Quality Standards for Particulate Matter: Final Rule, Federal Register, 78, 3086-3286, 2013.

Feinberg, S., Williams, R., Hagler, G. S. W., Rickard, J., Brown, R., Garver, D., Harshfield, G., Stauffer, P., Mattson, E., Judge, R., and Garvey, S.: Long-term evaluation of air sensor technology under ambient conditions in Denver, Colorado, Atmos. Meas. Tech. Discuss., https://doi.org/10.5194/amt-2018-12, in review, 2018.

Hand, J. L. and Kreidenweis, S. M.: A new method for retrieving particle refractive index and effective density from aerosol size distribution data, Aerosol Sci. Tech., 36, 1012-1026, 2002.

Hinds, W. C.: Aerosol Technology: Properties, Behavior, and Measurement of Airborne Particles, 2nd edn., Wiley-Interscience, New York, 1999.

Hogrefe, O., Drewnick, F., Lala, G. G., Schwab, J. J., and Demerjian, K. L.: Development, Operation and Applications of an Aerosol Generation, Calibration and Research Facility Special Issue of Aerosol Science and Technology on Findings from the Fine Particulate Matter Supersites Program, Aerosol Sci. Tech., 38, 196-214, https://doi.org/10.1080/02786820390229516, 2004.

Holstius, D. M., Pillarisetti, A., Smith, K. R., and Seto, E.: Field calibrations of a low-cost aerosol sensor at a regulatory monitoring site in California, Atmos. Meas. Tech., 7, 1121-1131, https://doi.org/10.5194/amt-7-1121-2014, 2014.

Jimenez, J. L., Jayne, J. T., Shi, Q., Kolb, C. E., Worsnop, D. R., Yourshaw, I., Seinfeld, J. H., Flagan, R. C., Zhang, X., Smith, K. A., Morris, J. W., and Davidovits, P.: Ambient aerosol sampling using the aerodyne aerosol mass spectrometer, J. Geophys. Res.Atmos., 108, 1-13, 2003.

Landen, D. D., Wassell, J. T., McWilliams, L., and Patel, A.: Coal Dust Exposure and Mortality from Ischemic Heart Disease Among a Cohort of US Coal Miners, Am. J. Ind. Med., 54, 727 733, 2011.

Le, G. E., Breysse, P. N., McDermott, A., Eftim, S. E., Geyh, A., Berman, J. D., and Curriero, F. C.: Canadian forest fires and the effects of long-range transboundary air pollution on hospitalizations among the elderly, ISPRS Int. J. Geo-Inf., 3, 713-731, 2014.

Lee, A. K. Y., Abbatt, J. P. D., Leaitch, W. R., Li, S.-M., Sjostedt, S. J., Wentzell, J. J. B., Liggio, J., and Macdonald, A. M.: Substantial secondary organic aerosol formation in a coniferous forest: observations of both day- and nighttime chemistry, Atmos. Chem. Phys., 16, 6721-6733, https://doi.org/10.5194/acp16-6721-2016, 2016.

Li, J. Y. and Biswas, P.: Optical Characterization Studies of a LowCost Particle Sensor, Aerosol Air Qual. Res., 17, 1691-1704, 2017.

Mätzler, C.: MATLAB Functions for Mie Scattering and Absorption, Research Report No. 2002-08, University of Bern, 2002.

McMurry, P. H.: A review of atmospheric aerosol measurements, Atmos. Environ., 34, 1959-1999, 2000.

McNamara, M. L., Noonan, C. W., and Ward, T. J.: Correction factor for continuous monitoring of wood smoke fine particulate matter, Aerosol Air Qual. Res., 11, 315-322, 2011.

Mamali, D., Marinou, E., Pikridas, M., Kottas, M., Binietoglou, I., Kokkalis, P., Tsekeri, A., Amiridis, V., Sciare, J., Keleshis, C., Engelmann, R., Ansmann, A., Russchenberg, H. W. J., and Biskos, G.: Vertical profiles of fine and coarse aerosol particles over Cyprus: Comparison between in-situ drone measurements and remote sensing observations[C]//EGU General Assembly Conference Abstracts, 9th EGU General Assembly, 2328 April, 2017 in Vienna, Austria, 19, 12966, 2017.

Mønster, J., Rosenørn, T., Svenningsson, B., and Bilde, M.: Evaporation of methyl-and dimethyl-substituted malonic, succinic, glutaric and adipic acid particles at ambient temperatures, J. Aerosol Sci., 35, 1453-1465, 2004.

Schwab, J. J., Crandall, B., Brandt, R., Spicer, J., Christophersen, M., and Beauharnois, M.: ASRC Air Quality Monitoring, State University of New York at Albany, May 2018, http: //atmoschem.asrc.cestm.albany.edu/ aqm/AQM_Products/, last access: 15 May 2018.

Seinfeld, J. H. and Pandis, S. N.: Atmospheric chemistry and physics: from air pollution to climate change, 3rd Edn., John Wiley and Sons, NJ, 2016.

Smith, A.: The Scattering of Light by Non-spherical Particles: Second Year Report, University of Oxford, 2009.

Sousan, S., Koehler, K., Thomas, G., Park, J. H., Hillman, M., Halterman, A., and Peters, T. M.: Inter-comparison of low-cost sensors for measuring the mass concentration of occupational aerosols, Aerosol Sci. Tech., 50, 462-473, 2016a.

Sousan, S., Koehler, K., Hallett, L., and Peters, T. M.: Evaluation of the Alphasense optical particle counter (OPC-N2) and the Grimm portable aerosol spectrometer (PAS-1.108), Aerosol Sci. Tech., 50, 1352-1365, 2016b.

Sun, Y., Zhang, Q., Macdonald, A. M., Hayden, K., Li, S. M., Liggio, J., Liu, P. S. K., Anlauf, K. G., Leaitch, W. R., Stef- 
fen, A., Cubison, M., Worsnop, D. R., van Donkelaar, A., and Martin, R. V.: Size-resolved aerosol chemistry on Whistler Mountain, Canada with a high-resolution aerosol mass spectrometer during INTEX-B, Atmos. Chem. Phys., 9, 3095-3111, https://doi.org/10.5194/acp-9-3095-2009, 2009.

Sun, Y. L., Zhang, Q., Schwab, J. J., Chen, W. N., Bae, M. S., Lin, Y. C., Hung, H. M., and Demerjian, K. L.: A case study of aerosol processing and evolution in summer in New York City, Atmos. Chem. Phys., 11, 12737-12750, https://doi.org/10.5194/acp-1112737-2011, 2011.

Sun, Y. L., Zhang, Q., Schwab, J. J., Chen, W.-N., Bae, M.-S., Hung, H.-M., Lin, Y.-C., Ng, N. L., Jayne, J., Massoli, P., Williams, L. R., and Demerjian, K. L.: Characterization of near-highway submicron aerosols in New York City with a high-resolution aerosol mass spectrometer, Atmos. Chem. Phys., 12, 2215-2227, https://doi.org/10.5194/acp-12-2215-2012, 2012.

Thermo Fisher Scientific, Inc.: MIE pDR-1500 Instruction Manual, Thermo Fisher Scientific Inc., Franklin, MA, 2014.

TSI Inc.: Operation and Service Manual, DustTrak DRX Aerosol Monitor, Revision E, P/N 6008408, TSI Incorporated, Shoreview, MN,2017.

Wallace, L. A., Wheeler, A. J., Kearney, J., Van Ryswyk, K., You, H., Kulka, R. H., Rasmussen, P. E., Brook, J. R., and $\mathrm{Xu}, \mathrm{X}$.: Validation of continuous particle monitors for personal, indoor, and outdoor exposures, J. Expo. Sci. Env. Epid., 21, 4964, 2011.
Wang, X., Chancellor, G., Evenstad, J., Farnsworth, J. E., Hase, A., Olson, G. M., Sreenath, A., and Agarwal, J. K.: A novel optical instrument for estimating size segregated aerosol mass concentration in real time, Aerosol Sci. Tech., 43, 939-950, 2009.

Wang, Y., Li, J., Jing, H., Zhang, Q., Jiang, J., and Biswas, P.: Laboratory Evaluation and Calibration of Three Low-Cost Particle Sensors for Particulate Matter Measurement, Aerosol Sci. Tech., 49, 1063-1077, 2015.

Wang, Z. C., Calderón, L., Patton, A. P., Sorensen Allacci, M., Senick, J., Wener, R., Andrews, C. J., and Mainelis, G.: Comparison of real-time instruments and gravimetric method when measuring particulate matter in a residential building, JAPCA J. Air Waste Ma., 66, 1109-1120, 2016.

Weast, R. C. (Ed.): Handbook of Chemistry and Physics, 57th edition, CRC Press, Cleveland, 1976.

Zhang, X. and Kondragunta, S.: Temporal and spatial variability in biomass burned areas across the USA derived from the GOES fire product, Remote Sens. Environ., 112, 2886-2897, 2008.

Zhang, Q., Canagaratna, M. R., Jayne, J. T., Worsnop, D. R., and Jimenez, J. L.: Time-and size-resolved chemical composition of submicron particles in Pittsburgh: Implications for aerosol sources and processes, J. Geophys. Res.-Atmos., 110, 1-19, 2005. 